\title{
Cost Escalation in Cotton Cultivation: An Analysis
}

\author{
A.R. Reddy", D. Blaise and Anuradha N. \\ Division of Crop Production, ICAR-Central Institute for Cotton Research, Nagpur, India
}

*Corresponding author: ar.reddy@gmail.com

\begin{abstract}
There is a growing discontentment among Indian cotton farmers because of declining profitability. Increase in production costs, yield stagnation and volatile output prices have affected the net incomes adversely. In this study we analysed cost of cotton cultivation to elucidate reasons for cost escalation. Cost of cultivation data obtained from the Directorate of Economics and Statistics for the period 200001 to 2014-15 was used for the analysis. It was found that an increase in human labour wage rates was the major factor that contributed to cost escalation. Fertilizers were another factor that contributed to cost escalation. Selective mechanization for curtailing human labour consumption and judicious use of fertilizers are options to lower the cost of cotton cultivation.
\end{abstract}

Keywords: cotton, agriculture, cost of cultivation, input factors, human labour, fertilizer consumption

Costs incurred in cotton cultivation have a major role in deciding the profitability of cotton cultivation. Furthermore, it affects the livelihoods of more than 6 million cotton farmers, who are mostly small and marginal. There is a growing discontentment among the Indian cotton growers because profitability has declined over the years. Several studies at various levels reported cost escalations in cotton cultivation (Shende and Thakare, 2011; Balaji and Kumar, 2016; Narayanamoorthy, 2013; Suresh et al. 2014; Matode et al. 2015). Increasing cost of cultivation has serious implications and will affect the sustainability of cotton production. Hence, there is a need for an in-depth analysis to find out the major factors responsible for the escalation in cultivation costs. This study aims to (i) analyse the cost of cotton cultivation in the nine major cotton growing states of India and (ii) elucidate reasons for the cost escalation.

\section{Data and Methodology}

The study is based on the state-level aggregate data on cost of cultivation collected under the 'Comprehensive Scheme on Cost of Cultivation of Principal Crops' of Directorate of Economics and Statistics, Ministry of Agriculture \& Farmers Welfare, Government of India. The data on cost of cultivation was collected for cotton crop across the nine major cotton producing states in the country for the period 2000-01 to 2014-15 from the website of the directorate (https://eands.dacnet.nic.in). The average cost and net return from cotton cultivation were examined by constructing all-India level aggregates by using crop area in respective states as weight. The concept of Cost $\mathrm{C} 2^{1}$ was used to represent the total cost.

\section{Costs and returns in cotton cultivation}

At the national level, net income over the total cost (cost C2) was very low, even negative prior to 2003-04. (Fig 1). A steady increase in net income was observed after 2003-04 and continued till 2010-11. Although there was an increase in the cost of cultivation, farmers were getting a decent profit from cotton cultivation up to 2010-11. This was due to the increased costs being offset by an increase in yield and higher market price of seed

${ }^{1}$ Cost $C 2$ includes all actual expenses incurred in cost and kind, depreciation, rent paid for leased in land, interest on fixed capital, rental value of owned land and imputed value of family labour. 
cotton. Beyond 2011-12, net income began to flatten and from 2014-15 it became negative. Stagnation in the cotton yields and output price combined with an escalation in the cost of cultivation adversely affected the net income. As a result, cotton farmers either obtained lowered profit or incurred losses (2014-15).

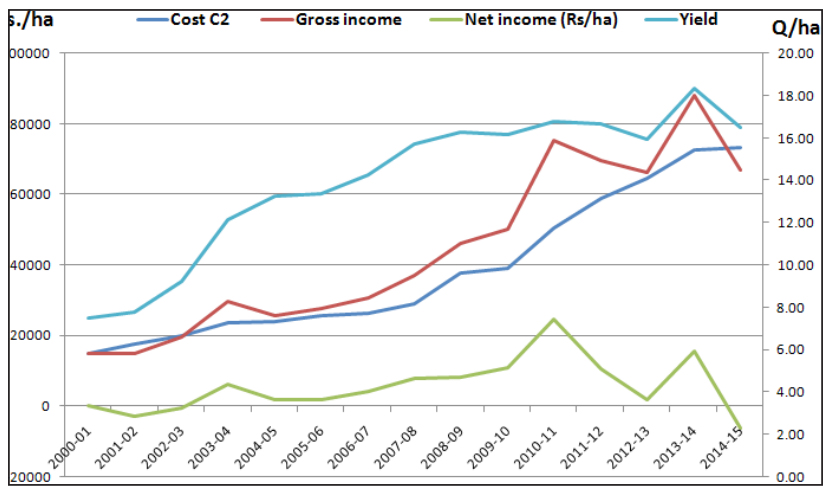

Fig. 1: Costs and returns in cotton cultivation in India

It is evident from the figure that the total cost (cost C2) started escalating from the year 2008-09. Before 2008-09, total cost was less than ₹ 30000/ ha. It increased to ₹ 37745/ha during 2008-09 and continued to increase at the rate of $13.2 \%$ per annum to reach ₹ 73179/ha in 2014-15. This was true with most of the cotton growing states. In six out of the nine cotton growing states, cost of cultivation of cotton started escalating from the year 2008-09. Hence to examine the changes that occurred in cost of cotton cultivation, average cost of cultivation of Triennium Ending (TE) 2007-08 was compared with TE 2014-15 (Table 1).

Table 1: Comparison of cost of cultivation (₹ per hectare) in major cotton growing states of India

\begin{tabular}{ccccc}
\hline State & TE 2007- & TE2014- & Increase & $\begin{array}{c}\text { \% } \\
\text { Increase }\end{array}$ \\
& $\mathbf{0 8}$ & $\mathbf{1 5}$ & & 128 \\
Andhra Pradesh & 34215 & 77980 & 43765 & 127 \\
Gujarat & 29243 & 66238 & 36995 & 121 \\
Haryana & 30465 & 67262 & 36797 & 246 \\
Karnataka & 15258 & 52813 & 37555 & 79 \\
Madhya Pradesh & 30240 & 54027 & 23787 & 224 \\
Maharashtra & 22287 & 72234 & 49947 & 102 \\
Punjab & 37069 & 74887 & 37818 & 216 \\
Rajasthan & 21016 & 66401 & 45385 & 178 \\
Tamil Nadu & 28373 & 78816 & 50443 & 159 \\
All India weighted & 27052 & 69956 & 42904 & \\
average & & & & \\
\hline
\end{tabular}

At the national level, cost of cultivation increased from ₹ 27052 in TE 2007-08 to ₹ 69956 in TE 201415 registering an increase of $159 \%$. Among the different cotton growing states, increase in cost of cultivation was the highest in Tamil Nadu followed by Maharashtra and Rajasthan. In percentage terms highest increase was observed in Karnataka followed by Maharashtra and Rajasthan. The least increase in cost of cultivation was observed in Madhya Pradesh followed by Punjab and Haryana.

\section{Factors contributing to increase in cost of cultivation}

Operational and fixed costs determine the total cost. Various components such as human labour, animal labour, machine labour, seed, fertilizer, manure, insecticides, irrigation charges and interest on working capital influence the cost of cultivation. Contribution of each component to the increase in total cost is given in Table 2 .

Table 2: Item wise breakup of cost of cultivation (₹ per hectare)

\begin{tabular}{|c|c|c|c|c|c|}
\hline & 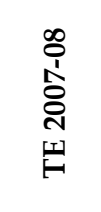 & 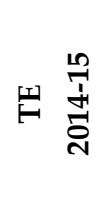 & 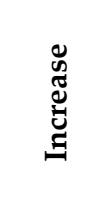 & 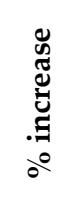 & 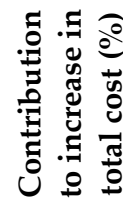 \\
\hline \multicolumn{6}{|l|}{ Operational Cost } \\
\hline Human labour & 7410 & 24691 & 17282 & 233 & 40.28 \\
\hline Animal labour & 2804 & 4164 & 1359 & 48 & 3.17 \\
\hline Machine labour & 1278 & 3789 & 2511 & 196 & 5.85 \\
\hline Seed & 2072 & 3747 & 1675 & 81 & 3.90 \\
\hline Fertilizers & 1757 & 5856 & 4099 & 233 & 9.55 \\
\hline Manures & 654 & 2042 & 1388 & 212 & 3.24 \\
\hline Insecticides & 1219 & 2729 & 1510 & 124 & 3.52 \\
\hline Irrigation charges & 724 & 1691 & 967 & 134 & 2.25 \\
\hline Miscellaneous & 19 & 63 & 44 & 238 & 0.10 \\
\hline $\begin{array}{c}\text { Interest on } \\
\text { working capital }\end{array}$ & 458 & 1212 & 754 & 165 & 1.76 \\
\hline Sub total & 18394 & 49984 & 31590 & 172 & 73.63 \\
\hline \multicolumn{6}{|l|}{ Fixed Costs } \\
\hline $\begin{array}{c}\text { Rental value of } \\
\text { land }\end{array}$ & 6756 & 15383 & 8626 & 128 & 20.11 \\
\hline Others & 1902 & 4589 & 2687 & 141 & 6.26 \\
\hline Sub total & 8658 & 19971 & 11313 & 131 & 26.37 \\
\hline Total Cost [11+12] & 27052 & 69956 & 42904 & 159 & 100.00 \\
\hline
\end{tabular}

It is evident from the data in Table 2 that the contribution of operational cost was to an extent 
of $74 \%$ and that of the fixed cost was $26 \%$. Among the individual factors, human labour contributed the maximum to cost increase in cotton cultivation. Human labour contributed nearly $40 \%$ of the increase in total cost. Cost of human labour increased by 233\% from TE 2007-08 to TE 2014-15. Rental value is another component which contributed $20 \%$ of the increase in total cost. It increased from ₹ 6756 per ha in TE 2007-08 to ₹ 15383 in TE 2014-15. Among the other components, cost of fertilizers contributed $9.55 \%$ to an increase in the total cost. It is clear from the analysis that the major factor which is responsible for an increase in total cost is the cost of human labour.

\section{Human labour cost}

Human labour is one of the major factors of production which accounts to about $30 \%$ of the total cost in cotton cultivation (Visawadia et al. 2006; Bhoi and Singh, 2005; Balaji and Kumar, 2016). Data in table 3 suggests that there was a substantial increase in the cost of human labour in cotton cultivation. The highest increase in the cost of human labour was observed in Karnataka followed by Maharashtra and Rajasthan. In Karnataka cost of human labour increased from ₹ 4098 in TE 2007-08 to ₹ 13595 in TE 2014-15 registering an increase of 332\%. Similarly Maharashtra and Rajasthan showed an increase of $327 \%$ and $275 \%$ in human labour cost. Lowest increase in cost of human labour was observed in Punjab, followed by Madhya Pradesh and Haryana. In Punjab cost of human labour increased by $136 \%$ while in Madhya Pradesh and Haryana it increased by $141 \%$ and $177 \%$ respectively.

From the data presented in Table 3, it is evident, that during the two periods TE 2007-08 and TE 2014-15, there was not much difference in the quantity of human labour utilized. At the national level, utilization of human labour increased by just $4 \%$ only. Out of the nine cotton growing states, only four states (Andhra Pradesh, Karnataka, Maharashtra and Rajasthan) recorded a marginal increase in human labour utilization. Where as in the other five states (Gujarat, Haryana, Madhya Pradesh, Punjab and Tamil Nadu) human labour utilization declined.

At the national level, human labour wage rate increased from ₹ 70 per manday to ₹ 227 per manday during the period of analysis. There was an increase of $224 \%$ in the wage rate during TE 2014-2015 when compared with that of TE 20072008. Highest increase in wage rate was observed in Karnataka (301\%) followed by Maharashtra (267\%), Haryana (234\%) and Tamil Nadu. Lowest increase in wage rate was observed in Punjab (172\%) and Gujarat (189\%). Thus, our analysis clearly points out to an increase in the wage rate that contributed to an increase in total cost of cultivation.

Rise in the wage rate is not specific to cotton cultivation. Agricultural wages rose steeply after 2007-08 (FICCI 2015). As the price elasticity of human labour is the lowest among various inputs (Srivastava et al. 2017); there is a greater scope to reduce cost of cultivation by controlling the wage

Table 3: Human labour utilized in cotton cultivation in different states of India

\begin{tabular}{cccccccccc}
\hline State & \multicolumn{3}{c}{ Cost of human labour (₹/ha) } & \multicolumn{3}{c}{$\begin{array}{c}\text { Quantity of human labour } \\
\text { (mandays/ha) }\end{array}$} & \multicolumn{3}{c}{$\begin{array}{c}\text { Wage rate } \\
\text { (₹/manday) }\end{array}$} \\
\cline { 2 - 11 } & TE 2007- & TE & \% Increase & TE & TE & \% increase & TE 2007- & TE & \% \\
& $\mathbf{0 8}$ & $\mathbf{2 0 1 4 - 1 5}$ & & $\mathbf{2 0 0 7 - 0 8}$ & $\mathbf{2 0 1 4 - 1 5}$ & & $\mathbf{0 8}$ & $\mathbf{2 0 1 4 - 1 5}$ & increase \\
\hline Andhra Pradesh & 8960 & 29203 & 226 & 100 & 102 & 2 & 93 & 287 & 209 \\
Gujarat & 8709 & 24102 & 177 & 131 & 124 & -5 & 67 & 193 & 189 \\
Haryana & 9713 & 26161 & 169 & 95 & 78 & -19 & 101 & 339 & 234 \\
Karnataka & 4098 & 17693 & 332 & 86 & 92 & 7 & 47 & 190 & 301 \\
Madhya Pradesh & 6889 & 16632 & 141 & 93 & 76 & -19 & 75 & 212 & 185 \\
Maharashtra & 5544 & 23660 & 327 & 105 & 122 & 17 & 53 & 193 & 267 \\
Punjab & 9584 & 22620 & 136 & 98 & 86 & -13 & 98 & 265 & 172 \\
Rajasthan & 7411 & 27813 & 275 & 82 & 105 & 28 & 90 & 265 & 196 \\
Tamil Nadu & 12168 & 39732 & 227 & 131 & 127 & -3 & 94 & 313 & 234 \\
All India & 7410 & 24691 & 233 & 107 & 111 & 4 & 70 & 227 & 224 \\
\hline
\end{tabular}


Table 4: Cost of fertilisers in cotton cultivation in different cotton growing states

\begin{tabular}{ccccccc}
\hline & \multicolumn{3}{c}{ Cost of fertilizers } & \multicolumn{3}{c}{$\begin{array}{c}\text { Quantity of fertilizers } \\
\text { (Kg nutrients /ha) }\end{array}$} \\
\cline { 2 - 7 } State & TE 2007-08 & TE 2014-15 & \% increase & TE 2007-08 & TE 2014-15 & \% increase \\
\hline Andhra Pradesh & 2531 & 7204 & 185 & 187 & 251 & 34 \\
Gujarat & 1861 & 4788 & 157 & 139 & 197 & 42 \\
Haryana & 1343 & 3095 & 130 & 105 & 130 & 23 \\
Karnataka & 1335 & 4549 & 241 & 91 & 146 & 60 \\
Madhya Pradesh & 2095 & 3385 & 62 & 158 & 113 & -29 \\
Maharashtra & 1526 & 7149 & 368 & 106 & 237 & 123 \\
Punjab & 1863 & 3669 & 97 & 153 & 185 & 21 \\
Rajasthan & 1067 & 2864 & 168 & 81 & 115 & 42 \\
Tamil Nadu & 2388 & 6637 & 178 & 186 & 208 & 11 \\
Wt average & 1757 & 5856 & 233 & 129 & 209 & 61 \\
\hline
\end{tabular}

rates. But this option is beyond the control of the farmer. Hence, the key in reducing cost of cultivation is a reduction in the utilization of human labour in cotton production. Cotton picking (harvesting) and weeding are two major field operations that requires maximum human labour. Many times farmers face labour shortage when these two operations need to be performed. Mechanical and chemical options can be exercised to curtail weeding cost (Blaise et al. 2005). For cotton picking, mechanical options are not available at present. Attention of the researchers needs to be focussed to develop mechanical pickers suitable to Indian conditions. Extending rural employment generation activities like MGNREGA to agriculture will also provide some support to reduce the human labour cost.

\section{Fertilizer Cost}

Fertilizers and manures are essential inputs for maintaining soil health and to realize potential cotton yields. Thus, these inputs also contribute to cost escalation. Data in Table 3 suggests that fertilizer costs alone contributed to $9.55 \%$ to the increase in cost of cultivation. The major fertilizers used in cotton cultivation include those that supply nitrogen, phosphorus and potassium. Apart from these, use of micronutrients such as zinc, boron and secondary nutrients such as sulphur have become prominent during TE 2014-15(Blaise et al. 2014). A comparison of the two periods indicates (i) an increase in the quantities of fertilizer consumed and (ii) increased fertilizer prices (Table 4). At the national level, fertilizer consumption in cotton cultivation increased from $129 \mathrm{~kg}$ of nutrients to
$209 \mathrm{~kg}$ of nutrients per hectare. Highest increase in the quantity of fertilizer used was observed in Maharashtra. Amount of fertilizer consumed in cotton production in Maharashtra increased from $106 \mathrm{~kg}$ of nutrients per hectare in TE 2007-08 to $237 \mathrm{~kg}$ of nutrients per hectare in TE 2014-15. Two major factors are responsible for the increase in fertilizer usage in cotton production. Firstly, the cultivation of high yielding hybrids had great nutrient demand (Kranthi 2014). Secondly, a decline in fertilizer productivity contributed to an increase in the amounts of fertilizer use (Blaise et al. 2014; Venugopalan et al. 2017). Alternate approaches are available that can facilitate judicious fertilizer use such as soil test based fertilizer management, green manuring, integrated nutrient management to reduce fertilizer input costs. Manures added 3.2\% to the increase in cotton cultivation. Cost of manures increased by $212 \%$, while it's quantity increased by only 15\% (Table 5). Recycling of crop residues and other on-farm wastes can be thought off to reduce the manure cost. Furthermore, manure application involves human labour. Retaining crop residues in the field, instead of disposing them off by burning can be thought of as a possible alternative.

\section{Cost of other inputs}

Cost of seed showed $81 \%$ increase while the quantity of seed used got reduced to $50 \%$ (Table 5). Increase in the area of $\mathrm{Bt}$ cotton hybrids resulted in the decrease in the seed quantity as the Bt hybrids require less seed per hectare (Venugopalan et al. 2017). But the cost of Bt hybrid seed is very high it caused increase in the seed cost. Seed cost 
Table 5: Percentage increase in cost and quantity of other inputs during TE 2007-08 to TE 2014-15

\begin{tabular}{ccccccccc}
\hline State & \multicolumn{2}{c}{ Seed } & \multicolumn{2}{c}{ Manures } & \multicolumn{2}{c}{ Animal labour } & $\begin{array}{c}\text { Machine } \\
\text { Labour }\end{array}$ & Insecticides \\
\hline & Cost & Quantity & Cost & Quantity & Cost & Quantity & Cost & Cost \\
\hline Andhra Pradesh & 92 & 3 & -29 & -40 & 91 & -22 & 127 & 41 \\
Gujarat & 42 & -47 & 218 & -2 & 42 & -43 & 149 & 75 \\
Haryana & 243 & -72 & 0 & 0 & -44 & -88 & 102 & 10 \\
Karnataka & 188 & -47 & 23 & -56 & 122 & -27 & 318 & 201 \\
Madhya Pradesh & -15 & -26 & 212 & 21 & 72 & -24 & 289 & 64 \\
Maharashtra & 85 & -45 & 425 & 125 & 32 & -1 & 551 & 511 \\
Punjab & 69 & -18 & 45 & -65 & 31 & -37 & 95 & 163 \\
Rajasthan & 543 & -74 & 572 & 186 & 91 & -21 & 143 & 30 \\
Tamil Nadu & 130 & -58 & 715 & 175 & -44 & -80 & 105 & 153 \\
Wt Average & 81 & -50 & 212 & 15 & 48 & -15 & 196 & 124 \\
\hline
\end{tabular}

contributed $3.9 \%$ to the cost escalation. Highest increase in seed cost was observed in Rajasthan (543\%) followed by Haryana (243\%). Animal labour is another component which contributed $3.17 \%$ to cost increase. There was a $48 \%$ increase in the cost of animal labour used in cotton cultivation. But quantity of animal labour used reduced by $15 \%$. Machine labour cost experienced an increase of 196\% from TE 2007-08 to TE 2014-15. Increased use of tractors for field preparation and substitution of animal labour may have brought about this change. Machine labour contributed $5.85 \%$ to an increase in the total cost. Cost of insecticides added 3.5\% to the cost escalation. Cotton is a crop with several insect pests affecting it such as the bollworms and sucking pests. Therefore, several insecticide applications are done to protect the crop (Kranthi, 2014). The cost of insecticides used in cotton cultivation increased from ₹ 1219 in 2007-08 to ₹ 2729 per hectare in 201415 (124\%). Increased incidence of white flies, thrips and mealybug as well as prices of insecticides may have increased the cost.

\section{CONCLUSION}

Our analysis of the available data clearly indicates that the reduction in the net income in cotton cultivation is mainly due to the escalation in the cost of cultivation. Increase in the wage rate of human labour is the major cause for the escalation in the total cost when compared to other components. Curtailing the human labour cost is the key to reduce the total cost. Cotton picking and weeding are the two major operations which consume maximum human labour. Alternative approaches such as mechanization and use of chemicals can be adopted to reduce the cost. Extending the rural employment generation activities like MGNREGA to agriculture will also provide some support to reduce the human labour cost. Soil test based and new approaches such as real time application of fertilizers will help curtail fertilizer cost. Integrated pest management practices with low cost inputs need to be practiced to reduce the cost of pest management.

\section{REFERENCES}

Balaji, S.J. and Kumar, S. 2016. Constraints in Cotton Cultivation: Cost Issues and Options for Income Increments, Indian Journal of Agricultural Economics, 71(3): 361-373.

Bhoi, P. and J. Singh. 2015. Bt-Cotton and its Impact on Cost Structure and Profitability of Cotton Farming in Punjab Agriculture, Trends in Biosciences, 8(14).

Blaise, D., G. Majumdar, G. and Tekale, K.U. 2005. On-farm evaluation of fertilizer application and conservation tillage on the productivity of cotton + pigeonpea strip intercropping on rainfed vertisols of central India, Soil and Tillage Research, 84: 108-117.

Blaise, D., M.V. Venugopalan and A.R. Raju. 2014. Introduction of Bt cotton hybrids in India: Did it change the Agronomy?, Indian Journal of Agronomy, 59: 1-20.

FICCI. 2015. Labour in Indian Agriculture: Agrowing challenge, Report, Federation of Indian Chambers of Commerce and Industry. (http://ficci.in/spdocument/20550/FICCI-agriReport\%2009-03-2015.pdf)

Kranthi K.R. 2014. Cotton Production Systems - Need for a Change in India Cotton Statistics \& News, No. 38: 4-7.

Matode S.D., S.B. Aglawe, R.B. Walke, S.J. Kakde and Pawar, G.R. 2015. Temporal Changes in Economics of Production of Cotton and Hybrid Jowar Crops in Akola District, International Journal of Tropical Agriculture, 33(4): 2443-2448. 
Narayanamoorthy, A. 2013. Profitability in Crops Cultivation in India: Some Evidence from Cost of Cultivation Survey Data, Indian Journal of Agricultural Economics, 68(1): 104121.

Shende, N.V. and Thakare, S.S. 2011. Structural changes in Cost of Cultivation of Selected Crops in Vidarbha, Economic Review, 53(3).

Srivastava, S.K., Chand, R. and Singh, J. 2017. Changing Crop Production Cost in India: Input Prices, Substitution and Technological Effects, Agricultural Economics Research Review, 30 (Conference Number): 171-182.

Suresh, A., Ramasundaram, P., Samuel, J. and Wankhade, S. 2014. Cotton Cultivation in India since the Green Revolution: Technology, Policy, and Performance, The Journal of foundation for Agrarian Studies, 4(2).
Venugopalan, M.V., A.R. Reddy, K.R. Kranthi, M.S. Yadav, S. Vandana, and Dhanashree, P. 2017. A Decade of Bt Cotton In India: Land Use Changes and other Socio-Economic Consequences, in Sustainable Management of Land Resources : An Indian Perspective, Ed. G.P. Obi Reddy, N. G. Patil, and Arun Chaturvedi, Apple Academic Press Inc.

Visawadia, H.R., A.M. Fadadu and V.D. Tarpara. 2006. A Comparative Analysis of Production and Marketing of Bt Cotton and Hybrid Cotton in Saurashtra Region of Gujarat State, Agricultural Economics Research Review, 19 (July-December): 293-300. 